\title{
Coordination in Thought
}

\author{
Henry Clarke ${ }^{1}$
}

Received: 12 April 2018 / Accepted: 20 November 2019 / Published online: 9 December 2019

(c) The Author(s) 2019

\begin{abstract}
Coordination in thought is the treatment of beliefs by the believer as being about the same thing. Such treatment can be indirect, via an identity belief, or direct. Direct coordination presents a problem concerning how this treatment is justified. Dickie (Fixing reference, OUP, Oxford, 2015) accounts for the justification of coordination in terms of aptness to a motivational state: coordination serves to fulfil a need to represent things outside the mind. I argue that this account gets the problem coordination presents wrong, and so does not present an adequate solution. While the material of that account may be reconfigured to provide a more promising proposal, I argue that this depends on a specious psychology of belief, and will anyway end up being circular. I propose an account that, while similar in some ways, improves on both the official and reconfigured Dickie-style accounts, and points to some broader conclusions about the nature of rational cognition.
\end{abstract}

\section{Introduction}

Beliefs are mental states that are about, or refer to, things in the broad sense that encompasses objects, persons, places, times, and so on. It is possible for a believer to have, and highly likely that she will have, several beliefs that are about the same thing. Whether or not two beliefs are about the same thing, it is possible for the believer both to treat them as such and not to do so. The problem of coordination in thought concerns cases in which beliefs are treated as about the same thing, the matter of what they are in fact about aside.

In a recent discussion, Dickie (2015; unadorned page numbers are references to this text) picks out why coordination presents a problem by contrasting two ways of treating one's beliefs as being about a single thing that is 'essential to a right account of justification for our inferential practices' (80). One requires having a belief to the effect that the subject of one set of beliefs (Cicero, say) is identical to the subject of another set of beliefs (Tully). In such a case of indirect coordination, one believes

Henry Clarke

uctyhcl@ucl.ac.uk

1 Birmingham, UK 
that Cicero is Tully, and so also that everything one believes about Cicero is also true of Tully, and vice versa. In the case of direct coordination, one simply takes the beliefs to be about a single thing without an identity belief. This is shown in how the beliefs are taken as premises in inferences. One form an inference may have can be represented like this:

(i) $\mathrm{a}$ is $\mathrm{F}$

(ii) $\mathrm{a}$ is $\mathrm{G}$

(iii) Therefore, something is $\mathrm{F}$ and $\mathrm{G}$.

In this representation, the name 'a' appears twice in the premises of the inference to the generalised conclusion. Such an inference may be justified or not:

If you are not justified in treating the terms as co-referential, then even if they do co-refer, as far as you are concerned this will be a mere matter of luck...[A]n inferential move that will generate a true conclusion only if the subject is lucky is not justified... [I]f we are to explain what justifies a subject in moving from (i) and (ii) to (iii), we must explain what justifies a subject in treating token singular terms as co-referential. (ibid.)

And this explanatory task 'arises wherever the validity of an inference depends on the co-reference of token singular terms it contains' (ibid.).

The task cannot be undertaken by appeal to identity beliefs. At some point, inferences that involve treating beliefs as about the same thing must trade on identity, in Campbell's (1987/88) phrase, since identity premises must themselves be coordinated with the others. A believer can be justified in treating her beliefs as being about the same thing. But the obvious way for the justification to come about, an identity premise, cannot be the only way, and it is not clear what the other way might be. Hence coordination presents a problem.

Or does it? Linguistic terms belong to types, tokens of which have the same reference; so directly coordinated terms might be thought of simply as somehow involving type-identical terms, as in the double occurrence of ' $a$ ' in the schema above. ${ }^{1}$ But, as Dickie points out, 'the problem is that the relevant notion of sameness of type will have to be cashed out in terms of the notion of thoughts justifiably treated by the subject as about the same object, which is what we are trying to explain' (82). A different sort of solution holds that the justification 'rests on pre-existing unity relations between the beliefs - unity relations that are an artefact of the way these beliefs are formed'. 2 So, for example, if one has a body of coordinated beliefs formed on the basis of a stream of perceptual experience of an object, 'you take the property information delivered through the perceptual channel, and marshal it into

\footnotetext{
1 Fodor (2008), Sainsbury and Tye (2012), and Prinz (2002) can be seen as proponents of this sort of view, though they do not address the problem of coordination directly. It is possible that there might be a response to the circularity worry that Dickie outlines, though the issues are complex and it is not possible to provide a full discussion here. At the very least the circularity worry is a challenge that makes the appeal to types unattractive.

2 Dickie cites Campbell (op. cit.) and Recanati (2012). Lawlor (2001) argues for a similar view.
} 
a body of beliefs which you treat as about a single thing.... [Y] ]our justification for treating the premises as about a single thing comes from the underlying unity relations secured by the way the beliefs are formed'. The problem is that 'this picture can be sustained only if the underlying bundling of information is itself justified.... [I]f bundling together information into bodies of belief according to these strategies is something we just do, rather than something we are justified in doing-it is hard to see how an appeal to the unity the strategies deliver can play the suggested role' ${ }^{3}$ Neither proposal works, so it remains unclear how direct coordination is justified.

The aim of this paper is to approach this problem through a critical discussion of the solution proposed by Dickie. Thinking through its shortcomings will help with formulating a more promising solution.

Dickie's official account of justified direct coordination relies on the idea that believers have a basic need to represent things outside the mind. It combines this with the claim that bodies of belief - that is, networks of coordinated beliefs-are characterised by proprietary means of justification, which are specific ways in which a thinker is disposed to revise or maintain those beliefs in the face of new information. The idea, which will be set out in Sect. 2, is that these means of justification serve to fix the reference of the beliefs that make up the body of beliefs all together, so providing a reliable way of fulfilling the need, and so making the coordination of beliefs justified.

The objection to this account is that it rests on a mistaken conception of the problem. That coordination fulfils a need does not bear on the problem in the way that the account supposes. As I will argue in Sect. 3, what is needed is an indication of sameness of reference, and fulfilling the need to represent is orthogonal to this. The characterisation of beliefs that Dickie employs in this account might be reconfigured to give a different solution, on which the proprietary means of justification do the work. The problem is that they can do so only by presupposing what is to be explained. Showing this is the aim of Sect. 4. These objections motivate an alternative approach, presented in Sect. 5, on which it is the presence of the inferential dispositions distinctive of coordinated beliefs themselves that serve, under appropriate conditions, to indicate that the beliefs are about the same thing. This account overlaps with Dickie's in some respects, though the differences are significant and point to some more general conclusions about the nature of rational cognition.

\section{Dickie's Official Account}

I begin by setting out Dickie's official account. This has a number of components, so I will go over it in some detail.

Dickie begins by casting the justification of coordination (that is, direct coordination-I will usually drop this qualification) as an instance of a form of justification of behaviour, 'aptness in virtue of motivational state' (91). This is a

\footnotetext{
3 Proponents of the appeal to mental files go further than Dickie's brief remarks suggest. I note also that 'structural unity' need not be tied to how beliefs are formed; this point is discussed below.
} 
generalisation of what may be the more familiar idea of aptness in virtue of justification by-intention. This comes in two degrees of strength. Behaviour is weakly justified by an intention 'just in virtue of being selected by the intention'. Behaviour is strongly justified by an intention if and only if '(a) it is weakly justified by the intention, and (b) it is a reliable means to the intention's fulfilment' (86).

Dickie elaborates the notion of selection by intention by responding to an objection:

Why think that 'selected by' means anything more than just 'caused by'? And if 'selected by' just means 'caused by', why think that the notion of weak justification is genuinely normative? (94-5)

In response, Dickie sketches a 'generic' notion of guidance, in the form of a schematic description of a mechanism that is guided by a motivational state. Such a mechanism

(A) has a goal-representation (i.e. an representation of the end-state of a process),

(B) has a feedback mechanism that generates information about the current status of the system, and

(C) behaves in a way jointly determined by the goal represented and information about current status, in such a way that

(D) the behaviour determined by the goal-representation and the feedback mechanism tends towards the end-state.

Dickie emphasises that 'guidance is reason-generating only where the goal-representing state is a conscious personal-level state of a subject. When the goalrepresenting state $i s$ a state of this kind, we say that it provides a "reason" for the actions to which it gives rise' (98).

Behaviour is a reliable means of fulfilling a guiding intention when the (D)tendency is a non-lucky way of fulfilling the motivational state. There may be tricky questions about how exactly to understand reliability and non-luckiness, but I will take it as understood for present purposes.

Justification as aptness to a motivational state is, then, to be understood as guidance on the (A)-(D) model. Dickie claims that not only intentions can figure as a guiding motivational state, but also needs-more precisely, basic needs. A basic need is 'a personal-level mental state which, like an intention, can guide action, but which, unlike an intention, does not have propositional content' (100). A specifically basic need-involving version of weak/strong justification by motivational state can be easily formulated (101-2).

When applied to coordination, aptness to guiding motivational state gives us the claim that 'the information-marshalling moves involved in direct coordination are motivated by the need to represent, and are justified because apt to their guiding motivational state' (103).

The need to represent is obviously important in the context of setting out her view of coordination, though Dickie provides little detail about it. We are told 
that thinkers have a basic need to represent objects or individual things, but not much more. Perhaps Dickie simply takes it as a given that we have such a need and what it is. Perhaps that is right; there may be no illuminating gloss on what a need is, but it is fairly straightforward to provide examples, like the need for water. And it is hard to imagine what a human life would be without the live possibility of forming beliefs (possessing knowledge) about individual things in the world around us. Dickie also does not really argue for the claim that '[d]irect coordination of information carried by perception and testimony into bodies of belief is guided by the need to represent' (ibid.), though one might take this to be supported by being part of (what may be) the best explanation. ${ }^{4}$

Dickie does offer more explicit support for the idea that coordination is apt to the need to represent. This involves two claims. One is REFERENCE AND JUSTIFICATION:

S's $\langle\alpha\rangle$ beliefs are about o iff justification for holding them converges on o (so that, in general, if $S$ is justified in believing $\langle\alpha$ is $\Phi\rangle, S$ will be unlucky if o is not $\Phi)$. (103)

Justification for a belief is to be understood as its being part of a body of beliefs. Bodies of belief, according to Dickie, have proprietary means of justification that converge on an object. A proprietary means of justification is a

specific 'trumping' route to justification-a route to justification for $\langle\alpha$ is $\Phi\rangle$ beliefs such that the subject is disposed to treat justification for believing $\langle\alpha$ is $\Phi\rangle$ generated by this route as overriding justification for believing $\langle\alpha$ is not $\Phi\rangle$ generated by any other. (51)

Such trumping routes to justification converge on an object when it excludes situations where o does not have the properties attributed to it.

The second claim is that, 'as a matter of empirical fact', coordinated bodies of beliefs 'match' properties of the object (that is, accurately attribute properties to their referents) picked out by the proprietary means of justification (102). Dickie argues for this empirical claim at some length, but we can grant it for present purposes. By contrast, surprisingly little is offered by way of support for the claim that bodies of beliefs have trumping routes to justification, given how important it is for supporting the view of coordination. I will return to this in Sect. 4.

With these claims in place, the account of coordination as apt to fulfil the need to represent runs as follows. Bodies of belief are constituted by beliefs that are directly coordinated. They have trumping routes to justification that determine the reference of those beliefs. So coordinating beliefs is part of what gets them their referential content, so what makes them represent things, thus fulfilling the need. When

\footnotetext{
${ }^{4}$ One problem that might be explored further turns on the idea that the need is a state identified in terms of its content, its fulfilment condition (to represent things outside the mind), though Dickie does not make it clear how the interactions between this state and the other parts of the mechanism are contentinvolving. The interaction is presumably also a causal one, but nothing is said about how it is both causal and content-involving.
} 
the proprietary means of justification is in empirical fact reliable, then the need is fulfilled in a non-lucky way. Therefore, on Dickie's account, coordination is both weakly and strongly justified by aptness to the need to represent. Does this solve the problem?

\section{The Reason's Not the Need}

Dickie sets out the problem of coordination as concerning the justification of coordination behaviour (or 'information-marshalling moves'). By itself, this is unobjectionable. What is objectionable, however, is the move from this to the idea that the kind of justification we are after is justification as aptness. While it may seem a little high-handed to say that Dickie's solution is based on a mistaken conception of the problem, this can be shown by looking again at Dickie's introduction of the problem in terms of the contrast between direct and indirect coordination.

Dickie raises the problem of coordination as concerning inferential luck, then relates it to Anscombean practical knowledge (knowledge about what one is doing possessed in virtue of one's intentions), then casts coordination as behaving in a certain way, and the problem as one of justifying that behaviour, and finally comes up with coordination as a behaviour which is justified because apt to a motivational state (see 91). The question about what justifies coordination is raised in the context of its role in inference, and the answer fixes on how coordination is justified as a means to fulfilling a need. The objection I want to press is that the end-point does not have enough to do with the initial problem to count as a solution. Insofar as coordination raises a potential shortcoming in response to which justification is required, aptness to motivational state is irrelevant. The question is not just where there something positive we can say about coordination. It has specifically to do with the inferences distinctive of coordination: whether the presupposition made by those inferences is a rational one to make.

\subsection{Rationally Presupposed Identity}

In what sense do directly coordinated beliefs involve a presupposition?

Coordination is treating one's beliefs as being about the same thing. Treating one's beliefs as being about the same thing may be manifested in many ways, but one sure sign is that the thinker will be disposed to involve them in certain forms of inference. A clear example of such an inferential disposition is that involving the inference from two beliefs attributing distinct properties to something to the existentially general conclusion that there is something with both of those properties. The contrast between direct and indirect coordination lies in how those beliefs are combined to get that sort of conclusion. Indirect coordination occurs when there needs to be an identity belief; direct coordination occurs when there does not need to be an identity belief. In the case of indirect coordination, the identity belief is needed to indicate that the otherwise uncoordinated beliefs are about the same thing. Without this, the thinker would be only lucky if the inference turns out to be valid. This 
applies also in the case of directly coordinated beliefs-except there is no identity belief to do that job.

The problem of direct coordination comes from the fact that the role filled by the identity belief, to indicate sameness of reference in the inferences that the thinker is disposed to make, still needs to be filled when identity is presupposed by, and not represented as a premise in, the inference. The identity premise does this indirectly. The point about inferences trading on identity is that, at some point, all inferences that involve repeated 'terms', multiple beliefs about something, require something to play that role directly. It cannot be identity beliefs all the way down. This is the sense in which directly coordinated beliefs involve a presupposition: they are beliefs for which the thinker is disposed to make inferences that presupposes sameness of reference. The problem of direct coordination is to explain what fills this role-what indicates sameness of reference-in the direct case, given that it cannot be an identity belief that figures as a premise. ${ }^{5}$ The identity of what the beliefs are about is taken for granted, not explicitly entertained, but as the thinker is justified in doing so, there must be something that indicates that the identity obtains.

None of this diverges much from how Dickie sets up the problem. Now I want to add some additional detail. An inference might result in a true belief, and so be successful in some sense, but be lucky. There are two dimensions in which a disposition to engage in an inference that presupposes identity that is lucky would be lacking. The luckiness-making features would also obtain in the case that it does not result in a truth. So we can suspend the question of truth, and concentrate on potential shortcomings that such an inference may have. First, an inference being lucky is like a guess: the process leading up to it was not one that an epistemically responsible person would undertake. Second, drawing an inference without something to indicate that it is valid would be like finding oneself with an unaccountable conviction that something is the case: neither process nor result makes sense as a coherent part of the thinker's cognitive life.

The shortcomings concern epistemic responsibility and self-understanding. The problem of coordination is the problem of accounting for how inferential dispositions involving directly coordinated beliefs can have these properties, where this must be done in terms of a feature of those beliefs and not an additional belief.

There are obvious overlaps between the two properties: both have to do with rationality, with the reasons that bear on what we think and do, and both concern an apparent feature of our cognitive lives that stands in need of explanation, or else a revision in our self-image is called for. There is, nevertheless, an asymmetry between them. The question about responsibility cannot really be answered in the absence of some answer to the question about self-understanding; to have a sense of

\footnotetext{
${ }^{5}$ Is the presupposition a belief, or something else? While it is true that the presupposition has truth conditions, and involves a 'pro-attitude' towards that content, I am inclined to say that it is not a belief, or if it is, it is very different from normal beliefs. In any case, the point is that an identity which is presupposed in an inference does not figure in the inference as a premise, for the reasons rehearsed in Sect. 1. If the reader is puzzled about how the presupposed identity can interact with the inference if not as a premise, then they have grasped the puzzling nature of coordination. A positive account of coordination ought to resolve this puzzle. Dickie's account fails to do this, as I argue below; I attempt to do better in Sect. 5.
} 
what speaks in favour of an aspect of one's cognition is to some extent to understand one's thinking. By contrast, the question about self-understanding may be raised, and answered, independently of any view about the epistemic status of the presupposition. It matters for understanding rational cognition, even in the absence of a compelling answer to the question about epistemic responsibility. And while it is perhaps a given that coordination of beliefs is a rational undertaking (it really does make sense for us to treat our beliefs as being about the same thing), human fallibility means there is at least some room for it to turn out that inferences involve coordinated beliefs fail to be epistemically responsible. Again, that being the case would not obviate the question about self-understanding. It is possible to do something rationally and irresponsibly.

In drawing out this additional detail about the problem of coordination, I am not making any claims with which Dickie should disagree. All this is implicit in Dickie's own exposition of the problem, in particular the idea that coordination is justified only if it is luck-excluding. Before identifying the disagreement, I want to emphasise the following point of agreement: an adequate account of justified coordination needs to give an account of conscious, personal-level states of the thinker. Coordination is justified in the relevant sense when a thinker has reason to treat her beliefs in the way distinctive of direct coordination. This reason is an indication that the coordinated beliefs are about the same thing, and so what gives her a sense that the inferences she is disposed to make are valid. If this way of treating her beliefs is to form a coherent part of her cognitive life, it must therefore involve conscious, personal-level states, in the minimal sense that the indication of sameness of reference must be something of which thinker herself is aware.

An account that referred to elements of the thinker's sub-personal information processing mechanisms or to personal-level states without connecting these to her conscious mental life would fail by this standard. In the context of her official account, Dickie holds that '[g]uidance is reason-generating only where the goalrepresenting state is a conscious personal-level state of a subject' (99), which tallies with this idea. This does not mean denying that unconscious or implicit beliefs may be coordinated, or denying that information represented at the sub-personal level could be said to be coordinated when processed in some part of the thinker's cognitive system. It does mean denying that the problem we are concerned with here arises in such cases, since the question of the thinker's self-understanding does not apply there. It would require too long a discussion to clarify all the relevant issues concerning the status of sub-personal psychology and the distinction between conscious and unconscious beliefs, so I hereby merely flag this as an assumption I share with Dickie. In brief, coordination presents the problem of rationally presupposed identity when it occurs consciously, because the problem is to show how a thinker can treat her beliefs as being about the same thing in a way that she herself finds intelligible. $^{6}$

\footnotetext{
6 Thanks to anonymous reviewers for Erkenntnis for pressing me on various points in this section.
} 


\subsection{Aptness to the Need to Represent Does Not Solve the Problem}

To review: the problem of (direct) coordination is the problem of saying what it is about coordinated beliefs that would make the believer's disposition to employ those beliefs in inferences that presuppose sameness of reference (a) epistemically responsible and (b) an intelligible part of her cognitive life.

This allows us to pinpoint why aptness in virtue of the need to represent (in fact, any application of the idea of aptness in virtue of motivational state) does not solve the problem. Neither aspect of the problem is a matter of instrumental assessment. Showing how coordination behaviour is a means, reliable or otherwise, for achieving something the thinker is motivated (needs, intends, desires, or whatever else) to do is beside the point. This is an instance of a general principle that considerations bearing on the instrumental rationality of an action or behaviour do not answer all of the questions about the rationality of that action/behaviour-especially when it involves acting on a presupposition.

To illustrate this, consider another case of a rational action that makes a presupposition. Speech acts sometimes make presuppositions, and may be rational, justified actions. Suppose someone sincerely asks you: 'When did you stop smoking?' That question presupposes that at some point you were a smoker. Maybe the question puzzles you; you want to know how to make sense of their asking that question. An answer might well be: the inquirer intended to discover when you stopped smoking. That intention selects the speech act, so the act is weakly justified; asking the question is a reliable means of fulfilling the intention, so it is strongly justified as well (in the proprietary senses Dickie employs). But it says nothing as to whether the presupposition the act makes itself makes any sense. It says only that the act that made the presupposition made sense, under some description. If there is nothing to say about what the questioner took to speak in favour of the presupposition, then adducing the intention to discover whether you stopped smoking, and the selection of the speech act by that intention, leaves the speech act to that extent unexplained. We have not got a full account.

So the move from raising the question about what justifies coordination in the context of its role in inference to answering it by saying that coordination is justified as a means to fulfilling an intention embodies a mistake. Part of the reason for it may be the sort of examples Dickie uses to illustrate and motivate the account. ${ }^{7}$ Robin Hood is a skilled archer. He is attempting to hit the target. He comports his body just so, lets loose, and hits the bullseye. What justifies him in moving in that way was not that he happened to be successful, but that his movements were controlled by his intention of hitting the target, and were reliable in bringing off that intention. The example is linked to the problem of coordination because they can both be thought of in terms of the justification of behaviour. But the problem of coordination is not a

\footnotetext{
${ }^{7}$ See $87-89 \mathrm{ff}$.
} 
problem about a how a process achieves success. It is a problem about the nature of the process that may or may not achieve it. ${ }^{8}$

The dis-analogy between an archer's movements and a coordinated believer is that the latter but not the former is doing something that requires a particular sort of self-awareness which is not easily explained (Dickie's discussion of Anscombean practical knowledge is a missed opportunity in this regard, as it too is a form of selfawareness, specifically of what one is doing; Dickie does not carry this point over to her discussion of direct coordination). Overlooking this difference may make bringing in justification as aptness natural. But it should not be overlooked if we want an accurate conception of what is required.

It could be objected that the emphasis this places on inferences involving coordinated beliefs is a mistake. Dickie sometimes formulates the problem of coordination in terms of 'direct coordination strategies' (84) and 'information marshalling moves' (86), which might suggest that her focus is not on what results from coordination, but rather on what results in coordination. What results from coordination are dispositions to engage in inferences that rationally presuppose identity of reference. What results in coordination are exercises of a capacity to form bodies of belief that are involved in such dispositions. So perhaps it is unfair to reject her account as not properly rationalising the resulting inferences, when it is aimed at a rationalisation of the formation processes.

The difference between these two things is genuine, but shifting the focus to the formation of coordinated bodies of belief simply faces the same problem, which is that what generates the puzzle about justification concerns the presupposition that is active in the inferential dispositions that those formation processes deliver. The point may still be made that what is distinctively in need of justification about processes of forming coordinated bodies of belief concerns the fact that they result in beliefs involved in a particular pattern of inference.

Before concluding this part of the discussion, I want to emphasise that the objection here does not require or suggest any view on the relationship between theoretical and practical, or instrumental, forms of justification for belief. The objection here is not that Dickie's official account offers only instrumental justification (aptness to motivational state) whereas the problem concerns a specifically theoretical form of justification (reasons for something being true). The objection is that showing how coordination is justified because apt to a motivating state doesn't speak to what

\footnotetext{
${ }^{8}$ I take this opportunity to note a puzzling feature of Dickie's use of the archer example. We are meant to wonder what justifies the archer's movements, but we are not told what potential or actual shortcoming of those movements prompts that question. Suppose Robin Hood had missed. It might then appear that shooting in the way he did was a mistake. Being told that it is normally reliable but he was unlucky on that occasion would justify his actions. Or suppose he hit the target but adopted a highly unorthodox style. That might appear to be an irresponsible move (what with the fate of Sherwood Forest being at stake). But if it was a good way of achieving some other desired outcome, like preserving Robin's disguise, it would be justified. These are cases where the potential faults are answered by instrumental considerations. In the case of coordination, the question is raised in the context of non-instrumentally desirable features of the inferences distinctive of coordinated beliefs. Raising the question of justification generically, independent of specifying any specific shortcoming, may mistakenly encourage the view that instrumental justification is to the point.
} 
brings the justification of coordination into question. The justification Dickie's official account provides is justification for the wrong thing-it does not show that the presupposition made by the inferential dispositions distinctive of coordinated belief is justified. That is the case regardless of whether one wants to see the required justification as theoretical or practical.

Dickie has a number of things to say on the topic of practical justification for belief and how it might relate to theoretical justification, which turns on whether a belief might be practically justified (because, for example, it reliably fulfils a need), given that practical reasons for believing something may fail to rule out that belief's being false, and so not be truth-conducive. Dickie's view seems to be that practical justification can constitute theoretical justification, insofar as it is at least truth-conducive (see her discussion at 104-8). Whatever this view's merits, it does not speak to the objection because her official account's failure to address the presupposed identity is not due to its offering practical justification rather than theoretical justification for belief. No additional material for an explanation of how a believer may presuppose that her beliefs are about the same thing in an intelligible and responsible way can be found in Dickie's advocacy of the truth-conduciveness of some practical reasons for belief. In the next section, I will look at a way of reconfiguring Dickie's official account in a way that does do that. But Dickie's official account itself offers nothing, practical or theoretical, to show how a thinker who presupposes the identity of her beliefs in inference may make that presupposition responsibly and intelligibly.

The moral is that the instrumental considerations Dickie makes use of take us in the wrong direction. Bringing in aptness to the need to represent does not speak to the rationality of presupposing identity. And that is what a solution to the problem about coordination requires. The coordination of beliefs reliably fulfils the need to represent; grant that, and it remains unclear what indicates that the beliefs are about the same thing. I conclude that Dickie's account in terms of aptness to motivational state is based on a mistaken conception of the problem. If justification as aptness is the solution, coordination is not the problem.

\section{Reconfiguring Dickie's Account}

I have set out Dickie's account of the justification of coordination in terms of aptness to motivational state, and objected that it involves a mistaken conception of the problem. What is in need of justification is a presupposition, and that justification needs to take the form of an explanation of what indicates that beliefs taken to be about the same thing are about the same thing, where this cannot be an identity belief. This explanation is not supplied by showing that coordination serves some other end, as the account in terms of aptness to motivational state would imply.

However, it should be granted that Dickie's account involves materials that are clearly not a million miles away from what would supply a solution. The need to represent things outside the mind is, after all, something to do with representation, with having beliefs that refer to things. And it follows from what Dickie says about how that need is fulfilled that coordinated beliefs will have the same reference if they 
refer at all. Setting the need to represent to one side, the materials Dickie adduces supplies an account that works like this: as per REFERENCE AND JUSTIFICATION, beliefs get their referential content by being members of bodies of belief that have proprietary means of justification, or trumping routes to justification; bodies of belief are networks of coordinated beliefs; so coordinated beliefs have the same reference if they have any reference at all, because they get their reference in the same way; trumping routes to justification are conscious features of bodies of belief, and so there is a conscious feature of coordinated beliefs that indicates sameness of reference.

Call this the reconfigured account. Does it work?

When assessing the reconfigured account, it is important not to be overly distracted by the status of REFERENCE AND JUSTIFICATION. Dickie calls this a 'coordination principle', meaning that it coordinates two properties of a belief, its referential content and what justifies it. ${ }^{9}$ What matters for the reconfigured account is not the relationship between referential content and the means by which beliefs are justified, but rather the more specific claim that proprietary means of justification do reference-fixing work. One could grant that referential content and justification are related in as the principle says, but deny the specific claim. And that is what I propose to do.

There are two problems with the appeal to proprietary means of justification. The first is that there are arguably no such things. Bodies of coordinated belief do not go with particular trumping routes to justification, so that cannot be what indicates sameness of reference. The second problem is that, even if there are proprietary means of justification, they can only indicate sameness of reference if there is such an indication already in place.

The first objection requires contradicting a claim that Dickie explicitly makes, so it would help to lay out what she says in support of it. As it happens, this is not very much. It is mainly driven by the following example:

$[\mathrm{C}]$ onsider a situation where you believe $\langle$ That is round $\rangle,\langle$ That is orange $\rangle$, and $\langle$ That is rolling $\rangle$ by uptake from a current perceptual link, and an informant you know to be usually reliable comes in, sees what you are looking at, and says 'It's actually made of glass; it will shatter if it falls', so that you form additional beliefs $\langle$ That is made of glass $\rangle$ and $\langle$ That is fragile $\rangle$. These additional beliefs are justified by uptake from testimony rather than perception. But... you will-unless there is some unusual reason not to-treat perceptual justification for beliefs as trumping non-perceptual justification. (You pick the thing up and find that it yields to your grip; it falls to the ground with a thud, deforming a little but remaining intact. You revise your body of beliefs away from what your informant told you and towards the new perceptual information.) Preparedness to revise beliefs in the direction of the information delivered by perception-letting perceptual justification override non-perceptual-

\footnotetext{
${ }^{9}$ In its various forms, this principle is always stated in the form of a biconditional, although Dickie offers glosses on it that involve more explanatory terms like 'because' and 'in virtue of' (cf. note 21).
} 
is a mark of perceptual demonstrative thought: a body of beliefs is not a body of perceptual demonstrative beliefs unless its subject accords justification by uptake from a perceptual link this kind of trumping status. (50-1)

She then goes on to say that

[t]he notion of 'proprietary justification' for a body of ordinary beliefs is a generalization from this initial case. A body of ordinary $\langle\alpha\rangle$ beliefs is associated with a specific 'trumping' route to justification-a route to justification for $\langle\alpha$ is $\Phi\rangle$ beliefs such that the subject is disposed to treat justification for believing $\langle\alpha$ is $\Phi\rangle$ generated by this route as overriding justification for believing $\langle\alpha$ is not $\Phi\rangle$ generated by any other. (51)

The idea seems to be that the example describes a case where it is clear that the believer does indeed have a body of beliefs with a trumping route to justification, and that is enough to justify the claim that all (ordinary) bodies of belief are like this.

But the fact that, in the story, the thinker prefers the evidence of her own eyes over the say-so of an interlocutor does not really speak to that. It does speak to how, in general, the thinker is disposed to take more immediate evidence as over-riding less immediate evidence. The claim that bodies of belief feature proprietary means of justification would require that this preference applies specifically to immediate perceptual evidence, and specifically to cases of so-called 'perceptual demonstrative' bodies of belief, rather than to any body of beliefs. But there is no obvious reason to accept either claim on the strength of the example, unless one is already inclined to think that this must be a body of perceptual demonstrative beliefs that works in the way Dickie envisages. Without that, the intended generalisation is not at all compelling.

So the claim that there are proprietary means of justification lacks support. There are reasons for thinking that it is false, too. In fact, these can be found in Dickie's own discussion. Her core examples involve bodies of so-called 'perceptual demonstrative' beliefs, as above, and 'proper name-based' beliefs, 'thoughts of the kind standardly made available by grasp of, and standardly expressed using, proper names' (7). But these kinds overlap, and it will be rational not to treat any specific means of justification as a trump in such cases. It is not to the point to insist, as Dickie frequently does, that the account of coordination may be limited in the first instance to ordinary beliefs, where the italicisation marks a specific notion of ordinariness: beliefs concerning easily perceptible objects with ordinary causal profiles (not abstracta, not nano-scale concreta). The point is that ordinary cases are exactly of a kind which seem not to be neatly separated into perceptual demonstrative beliefs and proper name-based beliefs according to proprietary means of justification.

Take the following case. My parents recently adopted a dog, Worthington. I have encountered him on a number of occasions. Before I met him, I was told many things about him, using his name. I have a detailed body of beliefs that I take to be about one and the same dog. I am disposed to revise my beliefs when I have a 'perceptual link' with him (I discover from listening that he likes squeaky toys; I discover from my sense of smell that he has recently rolled in something unpleasant), 
and I am disposed to revise them from careful uptake of testimony (I find out that he went to the vet last Tuesday, and that he still barks when the post gets delivered). Is my Worthington body of beliefs a body of perceptual demonstrative beliefs, or proper name beliefs? Sometimes perception is more important, sometimes it is testimony that wins the day. So that body of beliefs must qualify as both-which is to say, neither.

There is nothing special about Worthington or this body of beliefs. Any body of beliefs will feature beliefs that bear any number of logical-inferential relations to other (potential) beliefs, which relations will be recognised and exploited by the thinker. Inference is a source of information that can over-ride any other source of justification for a body of beliefs. In the same way, more immediate evidence generally overrides less immediate evidence, so that more immediate evidence rests on a rich background of less immediate inferential support for the wide range of beliefs we have about anything we have any beliefs about (the necessary simplicity of examples used to illustrate claims about the psychology of belief make this point a little too easy to overlook). If we allow inference to be a source of information of this character, then there is no such thing as a body of beliefs with a specific trumping route to justification.

The objection so far does not rule out that some bodies of belief are limited in what can act as a 'trumping' justification in the ways that Dickie's categorisation of beliefs requires. So one response to the objection may be to insist that it applies locally, to those bodies of belief. Aside from the fact that there is no obvious reason to think that what makes for justified coordination may differ across different sorts of beliefs in the way this response supposes, the objection is not just that there are counter examples to the claim that bodies of belief have proprietary means of justification. The claim is general. Beliefs are either true or false, and so can stand in logical-inferential relations independently of the information streams that deliver them. We can draw on information we have to add to or modify bodies of beliefs opportunistically. ${ }^{10}$ To extend the Quinean image, the web of belief does not have its shape dictated by the way its strands were gathered. Proprietary means of justification conflict with this aspect of the psychology of belief.

There are, no doubt, ways that this first objection could be resisted, and perhaps there are more substantial motivations to be given. I do not propose to go over them, because the second objection concerns a more fundamental problem with the reconfigured account. In short, the only way of cashing out the notion of a proprietary means of justification for a body of beliefs that is adequate for supplying an indication of sameness of reference for those beliefs requires that there is already justification for coordinating those beliefs.

\footnotetext{
${ }^{10}$ I take the idea of opportunistic exploitation of information from Recanati's (2012) notion of an encyclopaedic mental file. There are similarities between other aspects of Recanati's views and the idea of proprietary means of justification, though I cannot explore them here. Millikan's (2000: 159-192) discussion of the epistemology of identity contains a number of insights relevant to the objection being put forward.
} 
First we need some clarity on what it would be for a coordinated body of beliefs to be associated with proprietary means of justification. I take it that a proprietary means of justification can be thought of as a set modifications to a body of beliefs that would be undergone in response to particular changes in the believer's informational state. A body of beliefs has a particular proprietary means of justification just in case the believer is disposed to make those modifications to that body of beliefs; call these justificatory dispositions. The obvious way to think of an informational state is as a set of propositions; a modification can be thought of as addition or subtraction of a proposition to or from that set (the attendant difficulties with individuating propositions can be suspended for our purposes).

It is crucial that a set of justificatory dispositions picks out a proprietary means of justification for a body of beliefs only if it bears on the body of beliefs as a whole. By that, I mean that the change made will potentially involve a modification not just of one belief, but all the beliefs in that coordinated body. It is not that justificatory dispositions are pairings of informational changes with beliefs considered singly, where the body of beliefs with which the means consisting of that set is associated is just a collection of such beliefs. That would lose sight of the idea of a means of justification for a body of beliefs, since the beliefs that the thinker would be disposed to modify will include beliefs that the thinker does not treat as being about the same thing; other beliefs will be modified as well. That would make the appeal to proprietary means of justification clearly over-extend.

The question is, how do justificatory dispositions apply to bodies of belief as a whole, rather than in virtue of applying to beliefs in that body considered singly? To apply to a body of beliefs as a whole, when the particular information changes occur, the thinker must be disposed not just to change one belief, but to consider its ramifications for potential changes to all of the beliefs. But why would she do so? There are two possibilities. Either (1) she is disposed to change potentially all the beliefs in that body of belief because she has a reason for treating them as being about the same thing, or (2) she is simply disposed to consider changes to that body of beliefs as a whole as a basic dispositional feature of her psychology.

Now we can frame the following objection. If the justificatory dispositions that constitute a proprietary means of justification are of the second variety, then there is no way for them to indicate sameness of reference. We simply have more dispositions the rationality of which we need to account for. Such justificatory dispositions would need to be supplemented with a conscious belief that justification converges on objects. The fact that the body of beliefs has justification that converges on an object does not appear in any way in the conscious features of the beliefs. So the obvious, and as far as I can see fatal, problem with this is that the attribution to thinkers capable of coordinated beliefs of a general belief that justificatory dispositions converge on objects is, to put it mildly, deeply implausible. ${ }^{11}$

\footnotetext{
11 Might the problem with a general belief about justificatory dispositions be solved by making it implicit? Dickie's 'methodological prejudice' against profoundly implicit propositional attitudes (see op. cit.: 17-9) would rule it out, but that aside, appealing to an implicit belief would make the account incomplete. A successful account of justified coordination needs to identify a conscious feature of coordinated beliefs that indicates sameness of reference, as discussed in Sect. 3.1. An implicit belief about them is not a conscious feature. Therefore, something would need to be in place that allows the implicit
} 
If justificatory dispositions that constitute proprietary means of justification are instead of the first variety, then they apply only if there is a reason for treating a body of beliefs as being about the same thing. But a reason for treating a body of beliefs as about the same thing is something that indicates that they are about the same thing. This way of understanding justificatory dispositions supplies an indication that avoids the attribution of wholly unrealistic beliefs to the thinker, but it suffers from the more straightforward problem that it requires there to be already something that indicates that those beliefs are about the same thing. The reconfigured account would then be viciously circular. ${ }^{12}$

To sum up, it is unlikely that there are proprietary means of justification, but if there are, then to play a role in justifying coordination, they require there to be something already in place that indicates that the body of beliefs is about the same thing. Either way, something independent of the justificatory dispositions must obtain that provides that indication. Dickie's official account therefore cannot be reconfigured to provide a more satisfactory solution to the problem of coordination.

\section{Coherence-Based Bootstrapping}

Dickie's official account of justified coordination as apt to the need to represent fails to address the problem. The materials of her account can be reconfigured to provide an account that does address the problem, but it turns out to be circular at best. What indicates sameness of reference must operate at a more basic level. In this section, I will propose an alternative account of coordination that meets this requirement. It shares some features with the Dickie-style accounts, which I shall note, but avoids the problems with those accounts.

Before presenting her view, Dickie mentions two attitudes towards the problem that she rejects (85). One is to deny that direct coordination is justified, but also to hold that it is the basis for the justification of inferences that 'keep faith' with it because simply an aspect of how we go on cognitively. The other is to hold that it is primitively justified, and so no explanation is needed. Dickie contrasts these two attitudes with a third: to explain what makes coordination justified. She adopts this attitude, and proceeds to offer her account, though her dismissal of the other two options is under-explained. It is perhaps motivated by the thought that we should

\footnotetext{
Footnote 11 (continued)

belief to become a conscious belief, thus returning us to the original problem, the deep implausibility of there being such a conscious belief.

12 Dickie discusses a circularity objection at 109-11, also in Dickie 2017, but nothing in either discussion lessens this problem. The circle at issue here is about a claim concerning the justification of coordination, while the circle Dickie discusses is about the status of REFERENCE AND JUSTIFICATION as a metasemantic claim, one that does not directly involve claims about coordination. Dickie's response, to the effect that the metasemantic claim is not meant as a reduction of epistemic to semantic properties, or vice versa, does not resolve, or even address, problem with the reconfigured account. It would anyway be surprising if Dickie did address the circle I identify here, since it arises in the context of an account (the reconfigured account) that Dickie does not countenance, either in her book or elsewhere.
} 
take direct coordination at face value, as a rational feature of our cognitive lives, and attempt to explain this fact. An explanation given on this basis should also work as an argument, as against those who are sceptical, for the idea that we do have reasons to treat our beliefs as being about the same thing in the way distinctive of direct coordination, and show that the justification provided is not primitive or mysterious.

However, Dickie's contrast of the three attitudes potentially obscures a kind of explanatory approach that is more promising than either of two accounts considered so far. One can accept that coordination is an aspect of how we do and must go on cognitively, but not say further that, as per the first attitude, the question of justification does not arise, or cannot be answered, as per the second. Rather, the fact that the coordination of our beliefs is a basic and compulsive part of our cognitive lives may be part of a story about its justification. This is the idea behind what Schroeter (2012) calls bootstrapping. ${ }^{13}$ A bootstrapping account works like this: take the presence of the inferential disposition to infer an existential generalisation from several beliefs for granted, add some conditions that obtain in part because these dispositions are present, and then show how those in conjunction gives rise to something that provides an indication of sameness of reference.

On the view I propose, the further conditions that do the work concern the role of the dispositions in supplying information that the thinker relies upon in responding to her various motivational states. This can be broken down into five parts:

- Coordinated beliefs are involved in dispositions to make inferences that presuppose identity.

- These inferential dispositions are such as to organise and provide information that may be relied upon by the thinker in pursuing her projects and realising her ideals.

- The presupposition made by the inferential dispositions can cohere or not cohere with the rest of the thinker's beliefs.

- Because the presupposition is made by inferential dispositions which organise and provide useful information that can cohere or not cohere with the rest of the thinker's beliefs, the default for the thinker is that the presupposition is true, which default may be defeated in the event of incoherence.

- There is an indication of sameness of reference sufficient for self-understanding when there is no consciously accessible defeater; this indication is sufficient for responsibility when there is no easy route to a consciously accessible defeater.

\footnotetext{
13 Dickie identifies Schroeter as an advocate of the idea that coordination is primitively justified (see 86 n4). This cannot be quite right, since Schroeter offers an account of how coordination is justified. Schroeter's view is that coordinated beliefs are collectively targets of interpretative axioms, including the principle that representations that get treated as being about the same thing are about the same thing. This appeal to interpretative axioms has obvious affinities with the reconfigured account discussed in the previous section, though it avoids employing a tendentious psychology of belief. One difficulty with it, however, is that the interpretative axioms would appear to have to be something of which the believer is aware, which is not particularly plausible. Strictly speaking, Schroeter's target is an explanation of 'samesaying', or 'coreference de jure'. So it may be that this difficulty does not apply when that is taken into account. The relations between these things and coordination in thought are interesting but beyond the scope of the present discussion.
} 
More needs to be said about every part, so let me take each in turn:

(1) For beliefs to be 'involved' in a disposition is merely a shorthand way of saying that the thinker is disposed to perform inferences of a certain sort with the beliefs as premises - in this case, of the kind that could be represented by a repeated term that refers to a particular.

(2) The simplest manifestation of this will be the inference to an existentially general conclusion that conjoins two properties that separate beliefs attribute to the particular in question. Whenever that inferential disposition is present, the beliefs are coordinated; there will be many more interesting inferences that will accompany it, being examples of inductive or abductive inferences which enable the believer to extend what they know and use the information that they have in novel circumstances that arise in the future, to make sense of their past experiences, and negotiate their way around their present environment. This is the sense in which inferential dispositions organise and provide information that may be relied upon by the thinker in pursuing her projects and realising her ideals. It would be a welcome task to spell this out in much more detail, but the general idea is that, if a thinker is motivated to act in certain ways or to attempt to bring about certain ends, then she will rely on information to do that, and her inferential dispositions, including those that presuppose identity, will be essential to her achieving her aims, and perhaps in having aims at all.

(3) The presupposition of sameness of reference made by the inferences the believer is disposed to make is not incorrigible. That is, it is possible for a believer to possess information that indicates that the presupposition is not correct. More likely is that the presupposition will cohere; but the point is that the likelihood of coherence makes the possibility, even if remote, of incoherence a live one. The presupposition fails to cohere when what it delivers cannot be true given what other information I am unwilling to give up. To illustrate: I have a body of beliefs about Worthington, whom I believe to be a dog I saw on days $\mathrm{d}_{1}, \mathrm{~d}_{2}$, and $\mathrm{d}_{3}$, if I find out that at least one of those dogs was not him, but not which one, then my disposition to infer that there is a dog that I saw on $\mathrm{d}_{1}, \mathrm{~d}_{2}$, and $\mathrm{d}_{3}$ must be dropped.

(4) Given the role of coordination in organising and providing information of use in pursuing a thinker's aims, the coherence of the presupposition with the rest of the thinker's information is a matter of concern; whether or not it coheres is something that a coordinated believer will be disposed to monitor. That is, the thinker will reliably modify her inferential dispositions on the basis of possessing information with which they fail to cohere. For this to be the case, the thinker does not have to represent those dispositions and evaluate their coherence. The modification on the basis of incoherent information can be treated as a basic feature of the thinker's psychology, just as the presence of the inferential dispositions may also be treated as basic. ${ }^{14}$ Similarly, the fact that the coherence of a

\footnotetext{
14 I propose a characterisation of a mind capable of coordinated thought in Clarke (2018). That characterisation does not address how monitoring is achieved as such, but can easily be extended by positing a functional relationship between the causal basis of the inferential dispositions and the types of rep-
} 
belief is something that the believer is disposed to monitor does not mean that some more basic evidence needs to be adduced to show that it is coherent. In the case of coordinated belief, it is hard to see how such a process would be so much as possible. Instead, the coherence of the presupposition can be taken (that is, it is responsible and rational to take it) as a given until shown to be incorrect. 'Shown to' can be interpreted in two ways: in terms of consciously accessible defeating information (as in the example given above), or with information that, while not consciously accessible at a given time, could be easily accessed, where what counts as 'easily' is not specifiable outside a particular epistemic context, and where 'access' depends on routes from the information that the thinker currently has via inference, imagination, or straightforward observation.

(5) The default correctness of coherent presupposed sameness of reference means that there is an indication of sameness of reference whenever the conditions sufficient for that default obtain. Because the presence of the inferential dispositions and the absence of a consciously accessible defeater are all aspects of a believer's conscious mental life, the indication it provides is sufficient for self-understanding. The coordinated believer does not simply find herself with unaccountable inferential dispositions; there is something to show that they fit in with what else she thinks and does. When there is no easily consciously accessible defeater, that presupposition is also epistemically responsible.

I will give this the slightly clumsy label of a coherence-based bootstrapping account. I take it that it is clear why it is coherence-based, and why it counts as a bootstrapping account. What indicates sameness of reference is the presence of the inferential dispositions themselves in a thinker that is motivated and concerned to monitor them, not an additional belief which acts as a premise in those inferences. What makes the presupposition rational is that nothing speaks against the inferential dispositions, and yet they are monitored and open to revision. Being disposed to change one's inferential dispositions in the face of evidence that the presupposition is incorrect, that the presupposed identity fails to obtain, allows the identity to play a rational role in a thinker's inferential dispositions without figuring as the content of a premise.

To elaborate this account further, I will briefly spell out three comparisons with Dickie's official and reconfigured accounts before drawing some more general conclusions.

The first two comparisons I want to draw turn on the two ways in which coherence-based bootstrapping is obviously very similar to those accounts: it makes appeal both to a thinker's motivational states, and to a particular sort of disposition.

Dickie's official account holds that coordination is justified when it is a reliable way of fulfilling the need to represent. That makes a thinker's motivation key to the account. In the same way, the coherence-based bootstrapping account requires

Footnote 14 (continued)

resentations of information that would put in place beliefs that would make the inferential dispositions incoherent. 
a thinker to have a rich set of motivational states the fulfilment of which depends on the organisation and supply of information through coordination. The key difference is that the appeal to motivational states in the latter account obviously does not involve casting the problem of coordination as one concerning instrumental considerations. The motivational states go towards turning the presence of the inferential dispositions into an indication of sameness of reference, not setting a standard of instrumental assessment for coordination.

Both the official and reconfigured accounts make use of the idea of justficatory dispositions, that constitute the possession by a body of beliefs of a proprietary means of justification. These justificatory dispositions may be thought of as a subset of the kind of monitoring dispositions that speak to the coherence or incoherence of the presupposition, though there is no need to make any commitment as to monitoring dispositions constituting a specific route to justification for a body of beliefs.

The third comparison turns on the fundamental disagreement concerning the role of reference-fixing properties of beliefs. On both the official and reconfigured accounts, what indicates sameness of reference is tightly connected to what fixes reference. Knowing or being aware of what fixes reference is not the stuff of basic rational cognition, but something which requires the kind of conceptual and theoretical sophistication needed for philosophical theorising of the kind Dickie's book exemplifies. By contrast, coordination is a basic, compulsive, and extremely easy to achieve feature of cognitive life. A correct account of coordination should therefore not turn on recondite claims about psychology or epistemology. Insofar as it requires bringing in conscious aspects of a thinker's mental life, awareness of conditions that fix reference is highly unlikely to be any part of this, given the theoretical sophistication needed to frame so much as a candidate theory of what goes towards fixing reference.

There is a rich tradition in thinking about cognition, often undertaken under the rubric of the theory of concepts and taking its inspiration from Frege's writings on sense and reference, that holds that questions about rational thought should, in some form, turn on (often highly tendentious) claims about the way in which intentional mental states such as beliefs get to have their referential properties (how they get to be about particular individuals, how they attribute properties to them, how they pick out particular logical operations). ${ }^{15}$ At least with respect to coordination, however, we have some evidence for thinking that this will not be the case. Focusing on reference-fixing properties is the wrong place to look for the kind of properties of beliefs that give the basic inferential structure of rational thought. The right place, if the coherence-based bootstrapping account is correct, is the role that the inferences have in a rational life.

This point raises issues that go far beyond the remit of the paper. My reason for raising it is precisely to indicate that the foregoing considerations on the problem of

\footnotetext{
15 Dickie obliquely locates her view within this tradition at $52 \mathrm{n} 18$, where she references Dummett, Evans, Campbell, and Recanati, all of whom explicitly take themselves to be developing Frege's notion of sense.
} 
coordination in thought bear on a wide range of issues concerning the proper understanding of the mind.

\section{Conclusion}

Coordination in thought presents a problem: what makes inferences that presuppose sameness of reference non-lucky? Dickie's official account holds that it is the fact that coordination helps fulfil the basic need to represent things outside of the mind. This fails to solve the problem because it shows only why coordination is instrumentally justified, and does not show how the presupposition it makes is a good one. A reconfiguration of the official account holds that proprietary means of justification serve to fix the reference of coordinated beliefs all together. But the notion of a proprietary means of justification for a body of beliefs lacks support, is of dubious coherence, and anyway cannot supply an indication of sameness of reference that does not depend on there already being one in place. Coordination must be explained in a more basic way. I have sketched a coherence-based bootstrapping account that fulfils this requirement. It is, at least, better than either Dickie's official account or the reconfigured account, and this provides some basis for thinking that reference-fixing properties are not explanatory of this basic feature of rational cognition.

Open Access This article is licensed under a Creative Commons Attribution 4.0 International License, which permits use, sharing, adaptation, distribution and reproduction in any medium or format, as long as you give appropriate credit to the original author(s) and the source, provide a link to the Creative Commons licence, and indicate if changes were made. The images or other third party material in this article are included in the article's Creative Commons licence, unless indicated otherwise in a credit line to the material. If material is not included in the article's Creative Commons licence and your intended use is not permitted by statutory regulation or exceeds the permitted use, you will need to obtain permission directly from the copyright holder. To view a copy of this licence, visit http://creativecommons.org/licen ses/by/4.0/.

\section{References}

Campbell, J. (1987/88). Is sense transparent? Proceedings of the Aristotelian Society, 88, 273-292

Clarke, H. (2018). Frege puzzles and mental files. Australasian Journal of Philosophy, 96(2), 351-366.

Dickie, I. (2015). Fixing reference. Oxford: OUP.

Dickie, I. (2017). Reply to Hofweber and Ninan. Philosophy and Phenomenological Research, 95(3), $745-760$.

Fodor, J. (2008). LOT2: The language of thought revisited. Oxford: OUP.

Lawlor, K. (2001). New thoughts about old things: Cognitive policies and the grounds of singular thought. New York, NY.: Garland.

Millikan, R. G. (2000). On clear and confused ideas: An essay about substance concepts. Cambridge: Cambridge University Press.

Prinz, J. (2002). Furnishing the mind. Cambridge, MA: MIT Press.

Recanati, F. (2012). Mental files. Oxford: OUP. 
Sainsbury, R. M., \& Tye, M. (2012). Seven puzzles of thought and how to solve them. Oxford: OUP. Schroeter, L. (2012). Bootstrapping our way to samesaying. Synthese, 189(1), 177-197.

Publisher's Note Springer Nature remains neutral with regard to jurisdictional claims in published maps and institutional affiliations. 